\title{
A SWOT Analysis of Development of Biomass Energy in Heilongjiang Province in China*
}

\author{
Zhen Hua \\ Harbin University \\ Harbin, China 150001
}

\author{
Man Lu \\ Harbin University \\ Harbin, China 150001
}

\begin{abstract}
China needs an enormous amount of energy to maintain the future economic developments. Heilongjiang province has the largest forest regions in China so that it has a huge potential of biomass energy resources to reduce the dependence on fossil fuels. This paper identifies four key aspects which affect the biomass energy development in Heilongjiang China such as strength, weakness, opportunity and threat, by using SWOT analysis. The paper may formulate countermeasures for developing biomass energy in Heilongjiang Province in China and is useful for the application nationwide.
\end{abstract} China

Keywords-SWOT analysis; biomass energy; Heilongjiang;

\section{INTRODUCTION}

Each factor in development of biomass energy in Heilongjiang Province in China is restricted by which includes strengths, opportunities, weaknesses and threats. As the features of the SWOT analysis contain these four aspects, this paper is trying to analyze the strategic environment of biomass energy development in Heilongjiang forest region was analyzed by SWOT analysis.

\section{RATIONALE OF SWOT ANALYSIS}

SWOT analysis has been considered as a strategic planning technique that used to help a person or organization identifying strengths, weaknesses, opportunities, and threats related to business competition or project planning. It is intended to specify the objectives of the business venture or project and identify the internal and external factors that are favorable and unfavorable to achieving those objectives. Users of a SWOT analysis may often ask and answer questions to generate meaningful information for each category to make the tool useful and identify their competitive advantages. The SWOT analysis has been described as the tried-and-true tool of strategic analysis.

The strength analysis mainly embarks on the enterprises' internal actual strength and comparison with its competitors; opportunities and threats analysis mainly focus on the external environmental changes and which has impacts on

*This paper is sponsored by Nation natural science foundation of China: research of China's coal supply scenarios forecasting and evaluation (2015GXS4D099); China Harbin University doctor research program: a study on the strategy of biomass energy development in Heilongjiang Province based on grey system (HUDF2018107). the enterprises themselves. In the process of the analysis, all the internal factors should be gathered and then they are ought to be evaluated by the external factors.

\section{A. Opportunities and Threats Analysis (OT)}

With the rapid development of the economy, society, science and technology, especially for the acceleration of the economic globalization, process of the integration, diversification of demand for global information, enterprises are now being in more open and complex external environment than ever, which had great impacts on the enterprises themselves. Thus, environmental analysis has been considered as a very important capability for each enterprise in current situation.

The trends of the environment development can be divided into two types: environmental threats, and environmental opportunities.

\section{B. Strength and Weakness Analysis (SW)}

It is one thing to identify attractive opportunities in an environment, quite another to own the competitive capability which is necessary to succeed in that opportunity. Every enterprise should check its advantages and disadvantages regularly, which can be done through making the "business management check list". This format can be used to check the marketing, finance, manufacturing and organizational capabilities of a business or an advisory body outside the business. Each element is graded: strong, slightly strong, medium, weak or weaker.

When two companies are in the same market or both of them have the abilities to provide products and services to the same customer group, if one of them has a higher winning interest rate or profit potential, then it is considered to have a competitive advantage over the other. In other words, the so-called competitive advantage refers to the ability of a company to surpass its competitors, which is conducive to the realization of its main goal — profitability. It is worth noting that, however, the competitive advantage does not necessarily lie entirely in higher winning rates, because sometimes companies prefer increasing market share or reward more especially to managers or employees. 


\section{SWOT ANALYSIS OF THE DEVELOPMENT IN BIOMASS ENERGY}

TABLE I. The SWOT ANALysis of DEVElopment of Biomass ENERGY IN HeILONGJANG

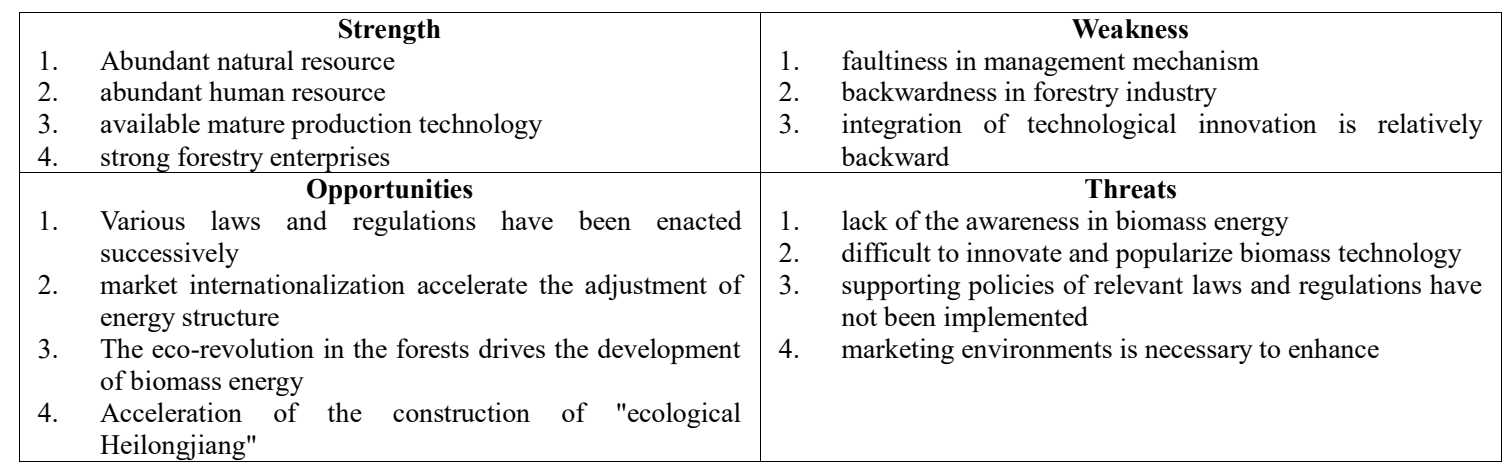

The four aspects shown in "Table I" will be analyzed in detail in the following parts.

\section{A. Strength Analysis}

The natural resources are abundant. As one of the important forest areas in China, the forest area of Heilongiiang province has abundant forest soil resources, extensive soil resources and biological diversity, which provides great space for further development of energy. Heilongiiang province has a relatively mature biomass technology, a good R\&D echelon of biomass technology, and the realization of "digital forestry" has laid a solid foundation for the development of the depth and breadth of forest biomass energy.

The human resources are abundant. Talent advantage, technological advantage and advantage in forming independently innovating for biomass energy technology, and a complete mechanism would be formed for the local economy in Heilongjiang province with biomass of form a complete set of mature new energy production process and technology, and continuously launch new energy technology with high added value products and clean energy services, in order to make important contributions to the development of local economy.

All sectors of society are promoting the development of forest biomass energy in various forms to improve the ecological environment. In this way, it can not only provide abundant clean energy and reduce environmental pollution, but also build a forest ecosystem with multiple functions, which will make a positive contribution for improving the severe ecological environment.

As a leading enterprise, the forest industry is an important driving force of the development of forest biomass energy. We should implement supporting policies, encourage mergers and reorganizations, foster leading enterprises and industrial cooperation, drive the forestry industry toward large-scale, collectivization and clustering, and improve the scale of operations and economic benefits.

\section{B. Weakness Analysis}

Currently, the management system is imperfect. The forest region in Heilongjiang province implements the administration management system of the integration of local government and state-owned enterprises. The difficulty of financing and the serious shortage of development funds is a great obstruction of breaking through the bottleneck of new technology of biomass energy, which mainly restricts the utilization and application of biomass energy technology in forest areas. For example, large-scale livestock and poultry farms, large and medium-sized biogas projects, commonly have the higher initial investment. If there is neither stable investment nor proper financing channel and the cost is reduced through preferential investment and financing policies, the mechanism cannot be established only by the enterprises. Thus, establishing corresponding investment and financing mechanism is a necessary condition of biomass energy technology industrialization.

The industry in the forest area is backward and lacks vitality. The forest area of Heilongjiang province is still in the stage of resource shortage. Acceleration of the fostering the key and leading enterprises in the biomass energy industry, and meantime, guiding numerous smaller biomass energy enterprise to adapt to the modern mass production requirements, asset restructuring, to develop in the direction of large-scale, intensive, and according to the present situation of the forest areas in Heilongjiang province, it is a very long way to meet the requirements of industrialization of biomass energy development.

The ability of efficient utilization of biomass energy is low, and integration of technological innovation is relatively backward. It can be seen from the technical environment of developing biomass energy in Heilongiiang province that R\&D ability and technology utilization level in Heilongjiang has already been at a higher level comparing with other province, however, at present, the high level of biomass energy technology in Heilongjiang province is mostly confined to the laboratory experiment stage, and it is difficult to apply it to the forest region in a large scale with immediate success. Therefore, the efficient utilization of biomass energy technology is still a big problem. 
At the same time, it can be seen from the analysis that the number of R\&D personnel and research institutions of biomass technology in Heilongiiang is considerable at present, but the integration capacity between personnel, technology and innovation is relatively low. Thus, this has led to the fact that some of the best people in the laboratory are researching biotechnology that is difficult to promote in the forest areas.

\section{Opportunity Analysis}

The financial crisis adjusted the structure of energy industry. The negative impact of the international financial crisis on China's economy has been emerging and getting worse. It has brought some negative impacts on China's energy development, but it has also brought important strategic opportunities for biomass energy. In order to solve some deep problems of the contradiction between supply and demand, the adjustment of energy structure should promote the development and utilization of biomass energy.

It is necessary to accelerate upgrading of biomass energy utilization technologies in forest areas, meantime, as well as developing efficient direct combustion technologies, power generation technologies, gasification and liquefaction technologies, and developing biogas power generation in centralized breeding plants to form and improve the industrial service system. And meantime, we will support the construction of demonstration projects for the comprehensive utilization of biomass. Recycling economy advocates low-carbon life development strategy, forest biomass energy plays a unique role and provides new and more investment opportunities in broader markets.

Various laws and regulations have been enacted successively. From the perspective of the political environment for the development of biomass energy in the forest region of Heilongjiang province, at both the national level and the industrial level, both the central government and the local government have attached great importance to the utilization of biomass energy. It then provides the policy guarantee for the development of biomass energy at different levels, no matter central or local government. The development of biomass energy accelerates the green revolution in forest areas in Heilongjiang even nationwide. The reform of wood burning in forest area is in urgent need of biomass energy and will solve the problem of employment to some extent. It can promote economic development and benefit the livelihood of workers in forest regions. And it is one of the most important routes to green revolution in forest regions in Heilongjiang province, therefore, it is considered as another important opportunity for the utilization and development of biomass energy. The promotion of use in biomass energy in the forest region not only solves the problem of the living energy of the workers in the forest region, but also expands the employment channels in the forest region and improves the life quality of the people in there. Accelerating the construction of "ecological Heilongjiang" brings important opportunities to the promotion of biomass energy. It is necessary for us to strengthen the protection of the ecological environment especially in the key ecological functional areas, key resource development zones, and areas with better ecological environment, it will be able to make full use of biomass energy forestry planting forest in non-forest land, as well as to explore the best combining site, energy construction and ecological construction at the same time of protecting forest resources, providing forest products with high added value, increasing the income of workers, to broaden the field of forestry development, the formation of the new economic growth point of forestry, promotion forestry in my influence in the national economy of China.

\section{Threat Analysis}

The supporting policies of relevant laws and regulations have not been implemented effectively. Although the central government attaches great importance to the development of biomass energy industry, meantime, it has adopted a series of policies or measures which made great positive progresses. However, a few departments are not mature enough to comprehend the policies for the development of the biomass energy industry, and some policies are not effectively implemented, it lacks detailed implementation rules, due to the poor operability and the short of reasonable and effective incentive policies. The deficiency of knowledge of biomass energy is one of the most important reasons. At present, the public has insufficient understanding of the importance of developing biomass in construction of new forest areas, energy conservation and emission reduction, and stimulating domestic demand. The exploitation and utilization of biomass energy has not been paid enough attention and widely recognized.

The biomass technology still needs innovation. At present, except for the mature technology of biogas and straw direct combustion power generation, other technologies are still in the initial stage of industrialization development, especially the core technology with independent intellectual property rights. At present, there is no detailed study on the availability of biomass energy resources in forest areas. Lack of detailed analysis of the rural biomass energy utilization technology, for the various use of rural biomass energy technology, economy, environment and the detailed evaluation, as well as to the different regions, the user, resource conditions, social and economic conditions of technology adaptability evaluation in detail, especially the development of forest biomass energy technology obstacles such as understanding is not enough.

Market conditions are not expected. Forest industry in Heilongjiang province is given the priority to decentralize management of small-scale peasant mode, biomass resources to unified collection and deployment of a conflict of interest the use of straw resource owners and companies don't coordinate each other, biomass resources cannot play a proper role lack of organization, collection and service system, which hindered the popularization and application of biomass energy in the forest areas. Additionally, the high cost and price of biomass energy technology is the biggest obstacle to the commercialization and application of the technology, comparing with other similar technologies, the biomass initial production cost of forest biomass energy utilization is much higher than that of fossil fuels. Forestry 
products are cheap in price, and biomass resources are cheap, while the technology and materials needed for energy conversion are expensive. Under the current pricing mechanism, the environmental and social benefits of biomass energy cannot be reflected.

\section{CONCLUSION}

The development of biomass energy in the forest regions of Heilongjiang province is affected by various internal factors. It has both internal advantages and disadvantages, as well as external development opportunities and threats. As a "special resource" of the forest region of Heilongjiang province, the development of biomass energy not only promotes the economic construction of the forest regions, but also has an important influence on the regional competitive advantage.

Generally speaking, the forest region of Heilongjiang province has a good environment for the development of biomass energy, which provides a good platform for the further development of biomass energy in the forest region. How to make good use of the opportunities to face the challenges and how to use the advantages to avoid the disadvantages in the development of biomass energy in the forest region will be one of the most crucial issue which should be taken into deep consideration. This requires further consideration from a strategic perspective. Meanwhile, the construction of a complete strategic system plays an important role in promoting the economic development of the forest region and the adjustment of the energy structure.

\section{REFERENCES}

[1] B. N. Smaragdakis. Analysis of solid biomass energy potential in Autonomous Province of Vojvodina. Renewable \& Sustainable Energy Reviews [J]. 2016, 57:186-191.

[2] A. Aslan. The causal relationship between biomass energy use and economic growth in the United States. Renewable \& Sustainable Energy Reviews [J]. 2016, 57:362-366.

[3] K. Tokimatsu. Global zero emissions scenarios: The role of biomass energy with carbon capture and storage by forested land use [J]. Applied energy, 2016, 185:1899-1906.

[4] GMJ. Herbert, AU. Krishnan. Quantifying environmental performance of biomass energy [J]. Renewable \& Sustainable Energy Reviews. 2016, 59:292-308.

[5] ZY. Zhao, H. Yan, WJ. Ling. SWOT analysis on the biomass power generation industry in China. Renewable Energy Resources. 2012(3).126-135.

[6] Yanjun Su. Spatial distribution of forest aboveground biomass in China: Estimation through combination of spaceborne lidar, optical imagery, and forest inventory data[J]. Remote Sensing of Environment. Vol.173, 2016, P187-199.

[7] Zhang Caiqin. Biomass and biofuels in China: Toward bioenergy resource potentials and their impacts on the environment[J]. Renewable and Sustainable Energy Reviews. 2017.8.

[8] Lv. Chun. Research on renewable energy development based on Grey relational analysis. Mathematics in practice[J]. 2018.03. vol.48. 